\title{
Synthesis of the cross-linked humic acid supporting palladium catalyst and its catalytic properties for Heck reaction
}

\author{
Qijie $\mathrm{Xu}^{1,2}$ Wenzhong $\mathrm{Shi}^{2}$, Yuanchen $\mathrm{Cui}^{{ }^{*}}$ \\ ${ }^{1}$ Henan University, Key Lab for Special Functional Materials, Ministry of Education, Kaifeng 475000 Henan China \\ ${ }^{2}$ Huanghuai University, Department of Chemistry \& Chemical Engineering, Zhumadian 463000, Henan China \\ "Corresponding author: qijie001@163.com
}

\begin{abstract}
Cross-linked humic acid supporting palladium (CL-HA-Pd) catalyst was prepared readily and characterized by infrared analysis (IR) and thermogravimetric analysis (TG). The catalyst could catalyze the Heck reaction of aryl halide or substituted aryl halide with vinyl compounds in $\mathrm{N}_{2}$ atmosphere; the yields were above $95 \%$. The catalyst could be recovered and reused 7 times with the Heck reaction of iodobenzene with acrylic acid, and the yield was above $75.6 \%$. The results showed that the catalyst had high catalytic activity even at low temperature of $62^{\circ} \mathrm{C}$ or with a small amount of the catalyst.
\end{abstract}

Keywords: Humic acid; epichlorohydrin; supporting palladium catalyst; Heck reaction.

\section{INTRODUCTION}

Humic $\operatorname{acid}(\mathrm{HA})$ as a heterogeneous mixture of organic widely exists in peat, lignite, stream, river, wetland, lake, and ground water. The molecular structure of HA contains double bonds and aromatic rings bearing various functional groups, such as carboxyl $(-\mathrm{COOH})$, hydroxyl $(-\mathrm{OH})$, amino $\left(-\mathrm{NH}_{2}\right)$, quinonyl $\left(-\mathrm{C}_{6} \mathrm{H}_{3} \mathrm{O}_{2}\right)$. These functional groups can form water-soluble, colloidal and water-insoluble complexes of different chemical and biological stability properties ${ }^{1-5}$. They were applied in agriculture ${ }^{6}$, forest ${ }^{7}$, biopharmaceutics $^{8}$, oil drilling ${ }^{9}$ and so on. HA can catalyze Knoevenagel and ClaisenSchmidt reaction ${ }^{\mathbf{1 0}}$, can also improve the reaction rate of hydrazine with 4-(N, N-dimethyl amine)benzaldehyde ${ }^{11}$.

However, the properties of instability at high temperature and dissolution in water affect the application of humic acid greatly. The objective of this study is to prepare the cross-linked humic acid (CL-HA) with epichlorohydrin as a cross-linking agent, and to form partial network structure. And then, the CL-HA-Pd catalyst is prepared by using the CL-HA supporting palladium chloride, and the catalytic properties of CLHA-Pd catalyst were studied.

\section{EXPERIMENTAL}

\section{Reagent and equipment}

Acrylic acid, styrene, dimethylformamide (DMF) and $N$-methyl-2-pyrrolidone (NMP) were distilled before use. Iodobenzne( $98 \%)$, bromobenzene(98\%), 1-iodo4-nitrobenzene(98\%), 1-bromo-4-nitrobenzene(98\%), 4-iodotoluene (98\%), and 1-iodo-4-chlorobenzene (98\%) were obtained from the Lancaster reagent and used as received. Acrylic acid, tetrabutyl ammonium bromides $(\mathrm{TBABr})$ and other reagents were obtain from were obtained from Aladdin reagent and used as received.

IR spectra were performed on an Avatar 360 Fourier transform infrared (FT-IR) spectrometer (Nicolet Co., USA). The atomic absorption spectroscopy (AAS) was performed on an AA-6601F spectrophotometer (Hitachi Co., Japan). The thermal analysis was performed on an EXSTAR6000 (Seiko Co., Japan) thermal analysis system at a heating rate of $10^{\circ} \mathrm{C} / \mathrm{min}$ in $\mathrm{N}_{2}$ atmosphere.
Synthesis of cross-linked humic acid with epichlorohydrin

Humic acid, epichlorohydrin were placed in the 100 $\mathrm{mL}$ three necks flask, then $10 \mathrm{~mL} 5 \% \mathrm{NaOH}$ solution was added in the mixture. The mixture was stirred at room temperature for $18 \mathrm{~h}$, filtered and washed with distilled water, ethanol, diethyl ether, and dried at 50 ${ }^{\circ} \mathrm{C}$ in vacuum oven for $24 \mathrm{~h}$. The product was characterized by the IR spectrum. The solubility properties of $\mathrm{HA}$ and CL-HA in water and $3 \% \mathrm{NaOH}$ solution were investigated, respectively. The results showed that they had great difference in solubility, which means that humic acid can dissolve in water and $3 \% \mathrm{NaOH}$ solution easily, and the cross-linked humic acid was hard to dissolve. It indicated that CL-HA was more stable in the solvent than the humic acid.

Synthesis of cross-linked humic acid supporting palladium complex

Cross-linking humic acid, distilled water was placed in the $100 \mathrm{~mL}$ three necks flask, after the mixture was stirred for $10 \mathrm{~min}$, palladium chloride was added in the mixture solution. The mixture was stirred at $85^{\circ} \mathrm{C}$ for 72 $\mathrm{h}$, filtered and washed with plenty of distilled water, and dried at $50^{\circ} \mathrm{C}$ in vacuum oven for $24 \mathrm{~h}$. The amount of palladium in complex is $0.38 \mathrm{mmol} / \mathrm{g}$ by AAS analysis.

Typical procedure of catalyst for the Heck arylation of aryl halide with olefins

The Heck arylation of aryl halide with acrylic acid

CL-HA-Pd complex (0.38 mmol\%), acrylic acid (6 $\mathrm{mmol})$, aryl halide $(5 \mathrm{mmol})$, tributylamine $(6 \mathrm{mmol})$ and DMF $(1 \mathrm{~mL}) / \mathrm{TBABr}(0.8 \mathrm{~g})$ (aryl iodides with DMF as solvent, aryl bromide with $\mathrm{TBABr}$ ) were taken in a three necks flask and stirred in $\mathrm{N}_{2}$ atmosphere for the fixed time(aryl iodides for $8 \mathrm{~h}$, aryl bromides for $12 \mathrm{~h}$ ). After the reaction the mixture was cooled to room temperature, $\mathrm{H}_{2} \mathrm{O}(25 \mathrm{~mL})$ and $\mathrm{Na}_{2} \mathrm{CO}_{3}(1 \mathrm{~g})$ were added. After stirring for $10 \mathrm{~min}$, the CL-HA-Pd complex was separated by filtration. The filtrate was treated with $3 \mathrm{~N}$ $\mathrm{HCl}(5 \mathrm{~mL})$. The precipitate was filtered, washed with $\mathrm{H}_{2} \mathrm{O}(2 \times 15 \mathrm{~mL})$ and dried in air to give transcinnamic acid. 
The Heck arylation of aryl halides with styrene/acrylamide

CL-HA-Pd complex (0.38 mmol\%), styrene/acrylamide $(6 \mathrm{mmol})$, aryl halide $(5 \mathrm{mmol})$, tributylamine $(6$ mmol) and DMF (1 mL)/TBABr $(0.8 \mathrm{~g})$ (aryl iodides with DMF as solvent, aryl bromide with $\mathrm{TBABr}$ ) were taken in a round bottomed flask and stirred at fixed time (aryl iodides for $8 \mathrm{~h}$, aryl bromides for $12 \mathrm{~h}$ ) in $\mathrm{N}_{2}$ atmosphere. The mixture was cooled to room temperature and dissolved in $\mathrm{Et}_{2} \mathrm{O}(30 \mathrm{~mL})$. CL-HA-Pd complex was recovered from the mixture by filtration, washed with $\mathrm{H}_{2} \mathrm{O}(2 \times 15 \mathrm{~mL}), \mathrm{EtOH}(2 \times 15 \mathrm{~mL})$ and $\mathrm{Et}_{2} \mathrm{O}(2 \times 15 \mathrm{~mL})$. The filtrate was treated with $3 \mathrm{~N} \mathrm{HCl}$ $(2 \times 15 \mathrm{~mL})$, brine $(3 \times 15 \mathrm{~mL})$ and dried over $\mathrm{MgSO}_{4}$. The solid product was obtained by recrystallization from $\mathrm{Et}_{2} \mathrm{O}$ and dried in air.

\section{RESULTS AND DISCUSSION}

\section{Characterization}

Various functional groups exist in the molecular structure of HA; these functional groups can be modified by chemical method. Amine group and carboxylic group of HA can interact with chloric atom and epoxy group of epichlorohydrin molecule, respectively. The cross-linked structure of HA (CL-HA) are formed. This CL-HA shows the better stability in acid solution or base solution. CL-HA is also characterized by IR spectrum and TG.

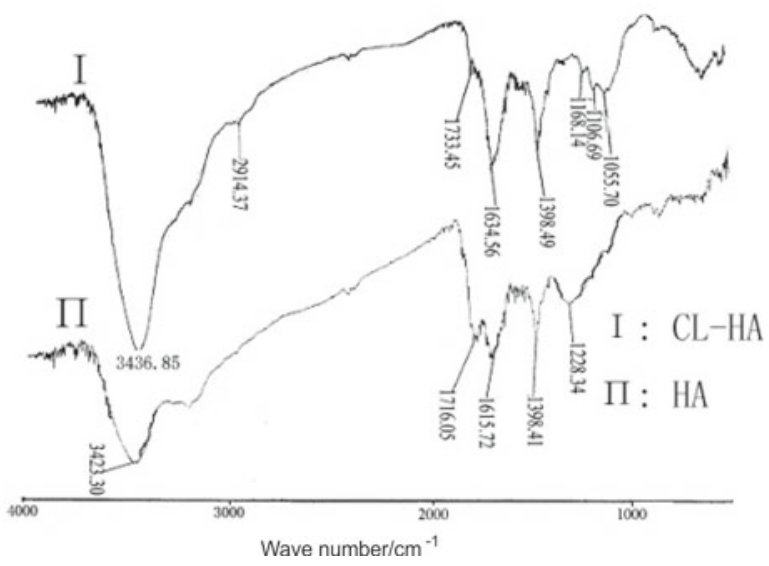

Figure 1. FTIR spectra of HA and CL-HA

IR spectrum of HA(II) differs from that of CL-HA(I) in Figure 1. The main features of these spectra and their corresponding assignments, according to Bellanmy ${ }^{\mathbf{1 2}}$, MacCarthy and Rice ${ }^{\mathbf{1 3}}$ Stevenson $^{\mathbf{1 4}}$ and Fan Kangnian ${ }^{\mathbf{1 5}}$, are the following: the peak of methylene in $2914 \mathrm{~cm}^{-1}$, this may be absorption peak of methylene of epichlorohydrin after cross-linked reaction of humic acid with epichlorohydrin. There are characteristic peaks of ester that $1733 \mathrm{~cm}^{-1}(\mathrm{C}=\mathrm{O}), 1055 \mathrm{~cm}^{-1}, 1106 \mathrm{~cm}^{-1}, 1168 \mathrm{~cm}^{-1}$ (streching vibrational of $\mathrm{C}-\mathrm{O}$ ). The contrast of I and II shows that $3400 \mathrm{~cm}^{-1}$ absorption peak in $\mathrm{I}$ is narrower than that in II. The reason may be that symmetric and anti-symmetric stretching of the primary amine of humic acid turn to vibrational stretching of secondary amine of cross-linked humic acid. And then the cross-linked humic acid can interact with palladium to form the complex easier because the cross-linked reaction weakens the interaction of hydrogen bond of amino with hydroxyl, carboxyl groups.

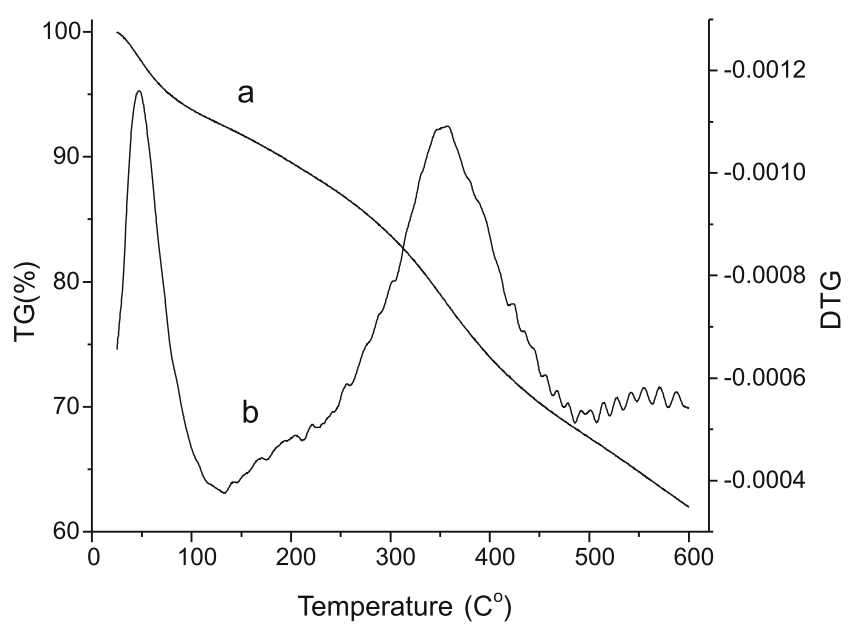

Figure 2. . TG curve of HA

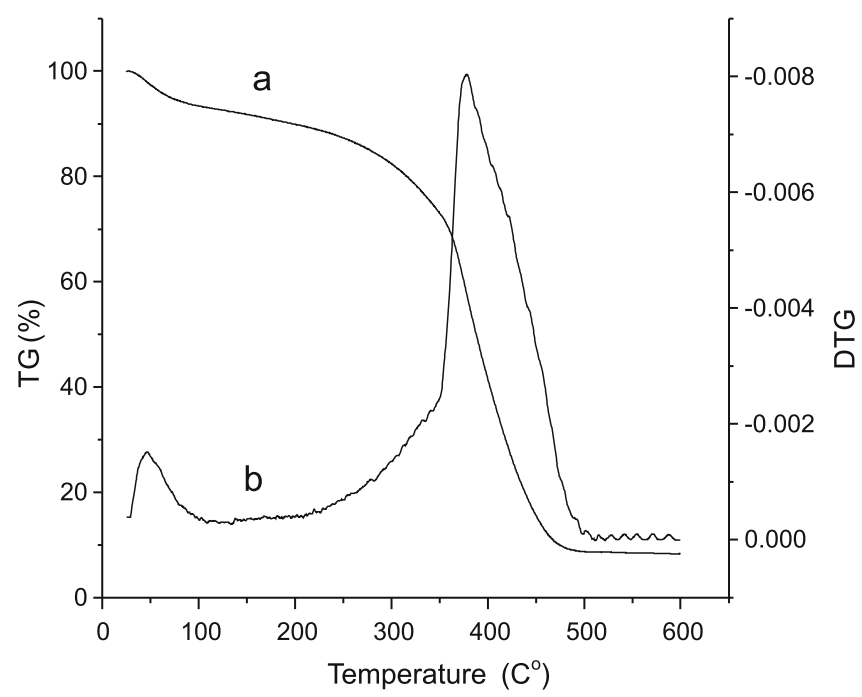

Figure 3. TG curve of CL-HA

Thermal stability of the catalyst has a great effect on its catalytic activity and recyclability because the Heck reaction is usually carried out under high temperature conditions. Figure 2 and 3 show that the thermogravimetric analysis (TG) of HA and CL-HA under $\mathrm{N}_{2}$ atmosphere. TG curves show that two materials are both stable up to $270^{\circ} \mathrm{C}$. However, there is an obvious flat in figure 3 and the rate of weight loss is slower than in Figure 2; it shows that CL-HA is more steady than HA, both materials are different in structure.

Catalytic property of cross-linked humic acid supporting palladium catalyst

The effect of temperature on catalytic property

The influence of temperature on the catalytic performance of CL-HA-Pd was investigated by using the Heck arylation of iodobenzene/bromobenzene with acrylic acid in fig.4. It can be seen from figure 4 that the yields of the product are all high within $70-100^{\circ} \mathrm{C}$ reach $100 \%$. However, the yield is $94.4 \%$ at $110^{\circ} \mathrm{C}$, perhaps with a side reaction at high temperature. But the yield of the product is $94.4 \%$ at $62^{\circ} \mathrm{C}$. Compared with the result reported by other researcher ${ }^{\mathbf{1 6 - 1 7}}$, the catalyst has better catalytic properties.

\section{The effect of time on catalytic property}

The effect of time on the catalytic property is studied by using the Heck reaction of aryl iodobenzene with acrylic 


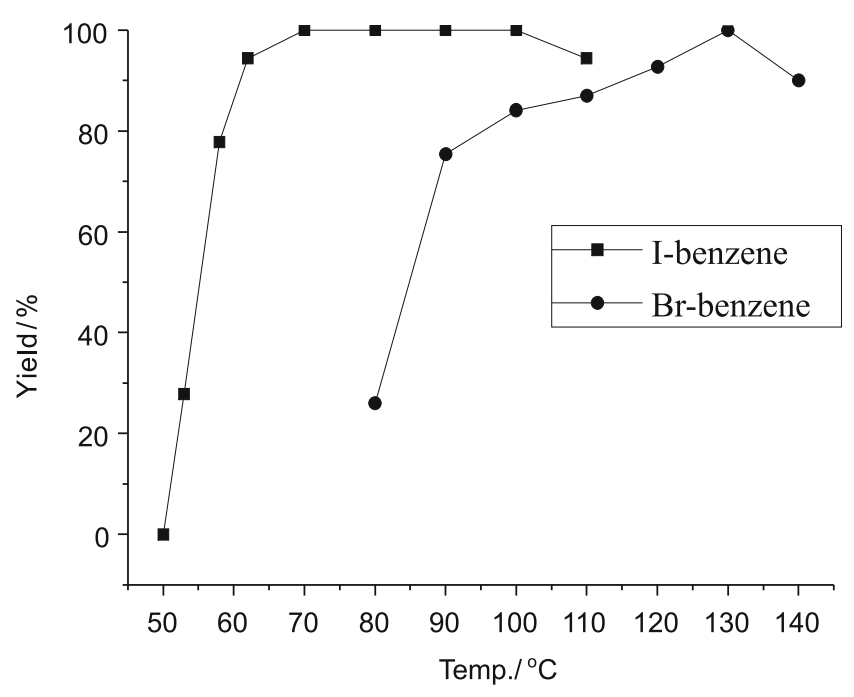

Figure 4. Effect of the temperature on catalytic properties

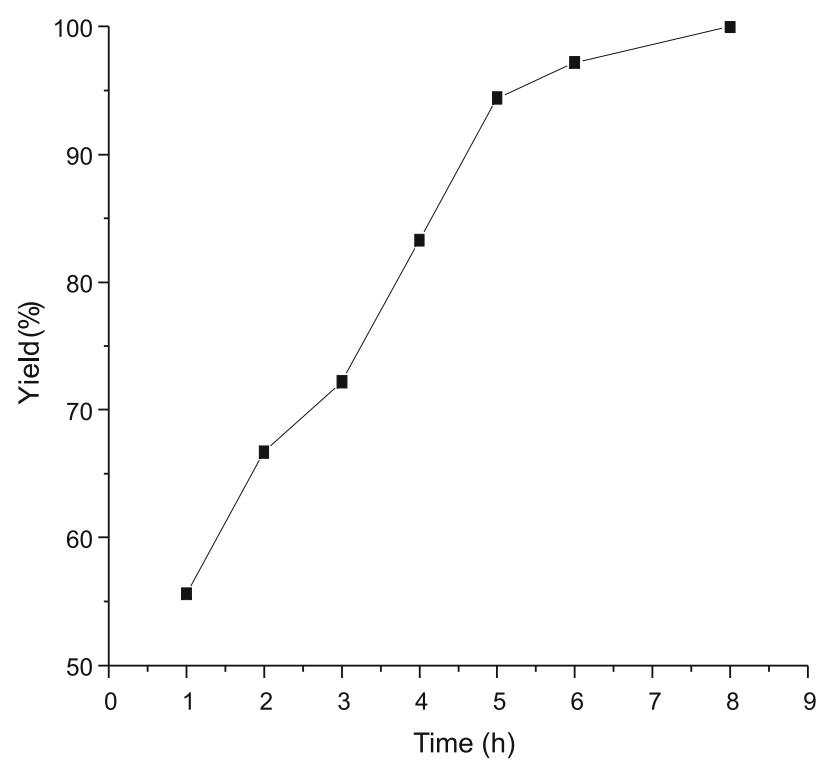

Figure 5. Effect of the reaction time on catalytic properties

acid in the reaction condition of $8 \mathrm{~h}, 90^{\circ} \mathrm{C}, 0.38 \mathrm{mmol}$ $\% \mathrm{Pd}$ and $\mathrm{N}_{2}$ atmosphere. It can be seen that the yield of the product increases slowly with 1 to $7 \mathrm{~h}$ in Fig.5. The yield of the cinnamic acid is above $95 \%$ in $5 \mathrm{~h}$. The reaction can be completed while the time increases to $6 \mathrm{~h}$. Compared with the similar lecture ${ }^{16}$, the reaction time by using catalyst of CL-HA-Pd is shorter and the catalytic activity of CL-HA-Pd is higher.

\section{The effect of the solvent on the catalytic property}

The effect of the solvent on the catalytic property is studied in table 1. The Heck reaction of iodobenzene with acrylic acid is carried out in the condition of crosslinked humic acid-Pd catalyst, $8 \mathrm{~h}, 90^{\circ} \mathrm{C}$, tributylamine as base, $\mathrm{N}_{2}$ atmosphere by using different solvents. It can be seen that the yield of product is highest by using DMF as solvent, so we choose DMF as the base of the reaction system.

Table 1. The effect of the solvent on the catalytic property

\begin{tabular}{|l|c|c|c|c|c|}
\hline Solvent & TBABr & DMF & NMP & dioxane & ------ \\
\hline Yield (\%) & 88.9 & 100 & 77.8 & 94.4 & 66.7 \\
\hline
\end{tabular}

The effect of the amount of catalyst on the catalytic property

The influence of the amount of catalyst on the catalytic performance of CL-HA-Pd was also studied by using the
Heck arylation of iodobenzene with acrylic acid (Table 2 ). With the amount of the catalyst ranging $0.38-0.038$ $\mathrm{mmol} \% \mathrm{Pd}$, yield of the cinnamic acid in the Heck reaction performed by CL-HA-Pd remains $100 \%$. Compared with the result of the similar literatures ${ }^{16-18}$, the catalyst has better catalytic activity even at low catalyst level ( $0.038 \mathrm{mmol} \% \mathrm{Pd}$ ) by CL-HA-Pd, and the yield of the cinnamic acid is still as high as $100 \%$.

Table 2. The effect of the amount of the catalyst on the catalytic property

\begin{tabular}{|l|c|c|c|c|c|}
\hline $\begin{array}{l}\text { Amount of } \\
\text { catalyst } \\
\text { (mmol\%) }\end{array}$ & 0.38 & 0.27 & 0.19 & 0.11 & 0.038 \\
\hline Yield (\%) & 100 & 100 & 100 & 100 & 100 \\
\hline
\end{tabular}

Recycling and reuse of the catalyst in the Heck reaction

The catalyst can be recovered easily from the reaction mixture by filtration. After washing with water, ethanol, the heterogeneous catalyst CL-HA-Pd can be reused under the same or similar conditions as for the initial run without regeneration. Recycling of the catalyst was examined for the reaction of iodobenzene with acrylic acid. It can be seen from fig. 6 that the catalyst can be recycled 7 times before the yield of the product drops down to $75.6 \%$. It shows that the catalyst has high activity and good recycling.

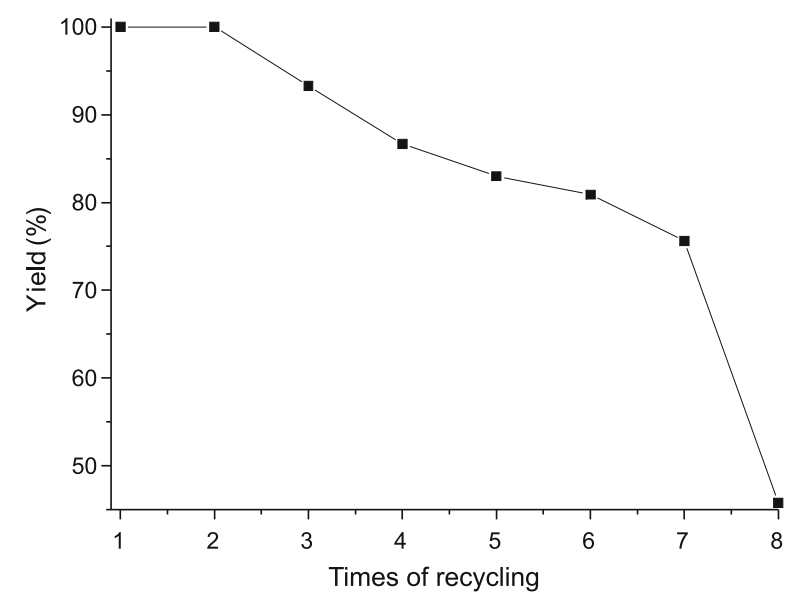

Figure 6. The curve of reusing catalyst

The Heck reaction of the different substituted aryl halide

Some scholars had researched that natural macromolecule supported palladium complexes catalyzed the Heck reaction of aryl iodobenzene with olefins ${ }^{18-21}$. The HA supporting palladium catalyst has the above properties that some scholars reported, but it can also catalyze the Heck reaction of bromobenzene with olefins. The cross-linked HA supporting palladium catalyst has better catalytic performance in table 3. It can be seen that HA and CL-HA supporting palladium catalyst all have high catalytic properties for the Heck reaction of aryl halide with donor groups or electro-attracting groups with olefins. CL-HA supporting palladium catalyst has higher catalytic activity. It can catalyze the Heck reaction of bromobenzene, substituted iodide and substitute bromide with acrylic acid, styrene and arylamide with high yields. But we found that the yield of the product is very low by using 1-iodo-4-nitrobenzene, 1-bromo-4-nitrobenzene with acrylic acid. If NMP, 1,4-dioxane, TBABr as solvent, the yield of the product is $100 \%$. The concrete reason will be studied continuously. 
Table 3. The Heck reaction of substituted aryl halides with olefins catalyzed by HA-Pd or CL-HA-Pd ${ }^{\mathrm{a}}$<smiles>[R]C=C=[X]c1ccc([R])cc1</smiles><smiles>[R]C=Cc1ccc([R]#CC)cc1</smiles>

\begin{tabular}{|c|c|c|c|c|c|c|}
\hline NO. & Aryl halide & Olefins & Products & Time(h) & Temp. $\left({ }^{\circ} \mathrm{C}\right)$ & Yield (\%) \\
\hline 1 & & $\mathrm{CH}_{2}=\mathrm{CHCO}_{2} \mathrm{H}$ & & 8 & 90 & $100(90.6)$ \\
\hline 2 & $\mathrm{H}_{3} \mathrm{C}-$ & $\mathrm{CH}_{2}=\mathrm{CHCO}_{2} \mathrm{H}$ & $-\mathrm{CH}=\mathrm{CHCOOH}$ & 8 & 90 & $93.8(77.4)$ \\
\hline 3 & $\mathrm{H}_{3} \mathrm{CO}-$ & $\mathrm{CH}_{2}=\mathrm{CHCO}_{2} \mathrm{H}$ & - $-\mathrm{CH}=\mathrm{CHCOOH}$ & 8 & 90 & $96.8(76.3)$ \\
\hline 4 & $\mathrm{Cl}-$ & $\mathrm{CH}_{2}=\mathrm{CHCO}_{2} \mathrm{H}$ & $\mathrm{CH}=\mathrm{CHCOOH}$ & 8 & 90 & $100(100)$ \\
\hline 5 & $\mathrm{O}_{2} \mathrm{~N}$ & $\mathrm{CH}_{2}=\mathrm{CHCO}_{2} \mathrm{H}$ & $\mathrm{CH}=\mathrm{CHCOOH}$ & 8 & 90 & $75(100)$ \\
\hline 6 & HOOC & $\mathrm{CH}_{2}=\mathrm{CHCO}_{2} \mathrm{H}$ & ) $-\mathrm{CH}=\mathrm{CHCOOH}$ & 8 & 90 & $100(100)$ \\
\hline $7^{b}$ & & $\mathrm{CH}_{2}=\mathrm{CHCO}_{2} \mathrm{H}$ & & 12 & 120 & $100(69.3)$ \\
\hline 8 & & $\mathrm{CH}_{2}=\mathrm{CHCO}_{2} \mathrm{H}$ & $\mathrm{HCOOH}$ & 12 & 120 & 33.3 \\
\hline 9 & HOOC & $\mathrm{CH}_{2}=\mathrm{CHCO}_{2} \mathrm{H}$ & $\mathrm{CH}=\mathrm{CHCOOH}$ & 8 & 120 & 100 \\
\hline 10 & & $\mathrm{CH}_{2}=\mathrm{CHCONH}_{2}$ & & 8 & 90 & 100 \\
\hline 11 & & $\mathrm{C}_{6} \mathrm{H}_{5} \mathrm{CH}=\mathrm{CH}_{2}$ & $=-10$ & 8 & 90 & 100 \\
\hline $12^{b}$ & & $\mathrm{CH}_{2}=\mathrm{CHCONH}_{2}$ & & 8 & 120 & 81.1 \\
\hline $13^{b}$ & & $\mathrm{C}_{6} \mathrm{H}_{5} \mathrm{CH}=\mathrm{CH}_{2}$ & $\Rightarrow=-10$ & 12 & 120 & 96.9 \\
\hline
\end{tabular}

a The reactions were carried out with HA-Pd or CL-HA-Pd $(0.38 \mathrm{mmol} \% \mathrm{Pd})$, aryl halide $(5 \mathrm{mmol})$, tributylamine $(6 \mathrm{mmol})$ and DMF $(1 \mathrm{~mL}) / \mathrm{TBABr}(0.8 \mathrm{~g})$ (aryl iodides with DMF as solvent, aryl bromide with $\mathrm{TBABr}$ as solvent) were taken in a round bottomed flask and stirred at fixed time(aryl iodides for $8 \mathrm{~h}$, aryl bromides for $12 \mathrm{~h}$ ) in $\mathrm{N}_{2}$ atmosphere.

b The amount of bromobenzene is $7 \mathrm{mmol}$, $\operatorname{TBABr}(0.8 \mathrm{~g})$ as solvent. Humic acid-Pd catalyst catalyzed the Heck reaction of iodobenzene with acrylic acid in the conditions of that by using DMF as solvent, tributylamine as base, $90{ }^{\circ} \mathrm{C}$ and $8 \mathrm{~h}$.

\section{CONCLUSIONS}

In summary, the CL-HA-Pd catalyst has been prepared easily by inexpensive support and exhibits high catalytic activity toward the Heck reaction of aryl halide with olefins in the $\mathrm{N}_{2}$ atmosphere. The catalyst keeps its catalytic activity in the Heck reaction of iodobenzene with acrylic acid even at a low temperature $\left(62^{\circ} \mathrm{C}\right)$ or with tiny amounts of the catalyst $(0.038 \mathrm{mmol} \% \mathrm{Pd})$. The catalyst can be reused many times, the yield was also $75.6 \%$ by using CL-HA-Pd as the catalyst that was recovered 7 times. The catalyst also catalyzed the Heck reaction of bromobenzene and substituted aryl halide with olefins.

\section{ACKNOWLEDGMENTS}

This work was supported by the Natural Science Foundation of Henan Province in China (Project1 No.0611020500, Project 2 No: 092300410121 \& Project 3 No: 112300410184).

\section{LITERATURE CITED}

1. Zeng, X.Ch. \& Cheng, Sh.X. (2002). The main category of humic acid. Humic acid, (2): 4-6. DOI: cnki:ISSN:1671-9212.0.2002-02-001.

2. Jansen, G., Paciolla, M. \& Ghabbour, E. et al (1996). The role of metal complexation in the solubility and stability of humic acid. Mater. Sci. Eng. C, 4(3): 181-187. DOI: 10.1016/ S0928-4931(96)00150-6.
3. Provenzano, M.R., D’Orazio, V. \& Jerzykiewicz, M., et al (2004). Fluorescence behaviour of $\mathrm{Zn}$ and $\mathrm{Ni}$ complexes of humic acids from different sources. Chemosphere, 55(6): 885-892. DOI: 10.1016/j.chemosphere.2003.11.040.

4. Gonzalez-Perez, J.A., Gonzalez-Vila, F.J., Almendros, G.(2004). The effect of fire on soil organic matter-a review. Environ. Int, 30(6): 855-870. DOI: 10.1016/j.envint.2004.02.003.

5. Golonka, I., Czechowski, F. \& Jezierski, A. (2005). EPR characteristics of heat treated complexes of metals with demineralised humic brown coal in air and ammonia atmosphere. Geoderma, 127(3-4): 237-252. DOI: 10.1016/j. geoderma.2004.12.005.

6. Ghouas, H., Haddou, B. \& Kameche, M., et al. (2012). Extraction of humic acid by coacervate: Investigation of direct and back processes. J. Hazard. Mater., 205-206: 171-178. DOI: 10.1016/j.jhazmat.2011.12.057.

7. Liao, Ch.H., Lu, M.Ch. \& Su, Sh.H. (2001). Role of cupric ions in the $\mathrm{H}_{2} \mathrm{O}_{2} / \mathrm{UV}$ oxidation of humic acid. Chemosphere, 44(5): 913-919. DOI: 10.1016/S0045-6535(00)00580-4.

8. Mirza, M.A., Ahmad, N. \& Agarwal, S.P., et al. (2011). Comparative evaluation of humic substances in oral drug delivery. Results in Phar. Sci, 1(1): 16-26. DOI: 10.1016/j. rinphs.2011.06.001.

9. Zhang, Q.L, Zhang, G.C. \& Ge, J.J. (2004). The application of humic acid in oil field. Drilling fluid \& Completion Fluid, 21(3):53-55. DOI: cnki:ISSN:1001-5620.0.2004-03-015.

10. Klavins, M., Dipane, J. \& Babre, K.(2001). Humic substances as catalysts in condensation reactions. Chemosphere, 44(4): 737-742. DOI: 10.1016/S0045-6535(00)00294-0.

11. Klavins, M. \& Babre, K.(2002). Decarboxylation and alkaline colour fading reactions in presence of humic sub- 
stances. Chemosphere, 49(6): 685-689. DOI: 10.1016/S0045-6535(02)00303-X.

12. Bellamy, L.J. The infrared spectra of complex molecules[M]. Chapman and Hall, London, 1975.

13. MacCarthy, P., Rice, J.A., Spectroscopic methods (other than NMR) for determining functionality in humic substances[M]. Wiley-Interscienece, New York, 1985.

14. Stevenson, F.J., Humus chemistry: genesis, composition, reactions[M]. Wiley-Interscience, New York, 1994.

15. Fan, K.N., An introduction to spectroscopy[M]. Edition 1, Higher Education Press, Beijing, 2001.

16. Hardy, J.J.E, Hubert, S. \& Macquarrie, D., et al. (2004). Chitosan based heterogeneous catalysts for Suzuki and Heck reactions. Green Chem. 2004, 6(1): 53-56. DOI: 10.1039/ B312145N.

17. Cui, Y.C. \& Zhang, L. (2005). Polyvinyl chloride-polyethylene-polyamine supported palladium complexes as high efficient and recyclable catalysts for Heck reaction. J. Mol. Catal. A: Chem, 237(1-2): 120-125. DOI: 10.1016/j.molcata.2005.04.050.

18. Kondolff, I., Doucet, H. \& Santelli, M.(2003). Tetraphosphine/palladium-catalyzed Heckreactions of aryl halides with disubstituted alkenes. Tetrahedron Lett., 44(46): 8487-8491. DOI: 10.1016/j.tetlet.2003.09.092.

19. Evangelisti, C., Panziera, N., Pertici, P., et al. (2009). Palladium nanoparticles supported on polyvinylpyridine: Catalytic activity in Heck-type reactions and XPS structural studies. Journal of Catalysis, 262(2): 287-293. DOI: 10.1016/j. jcat.2009.01.005.

20. Xu, Q.J, Zhang, L. \& Shi, W.Zh., et al. (2009). Catalytic performances of cross-linking humic acids supported $\mathrm{Pd} / \mathrm{Ni}$ bimetallic catalyst for heck reaction. Pol. J. Chem. Technol., 11(3): 22-26. 10.2478/v10026-009-0031-0.

21. Raja, M.U., Ramesh, R. \& Liu, Y. (2011). New binuclear Pd(II) thioamide complexes for the Heck reaction of aryl bromides. Tetrahedron Lett., 52(42): 5427-5430. DOI: 10.1016/j. tetlet.2011.07.080. 